\title{
Recurrent hypoglycemia secondary to metformin toxicity in the absence of co-ingestions: a case report
}

\author{
Sarah Aldobeaban ${ }^{1}$, Bandr Mzahim² and Abdussalam Ali Alshehri ${ }^{2 *}$
}

\begin{abstract}
Background: Metformin toxicity is well known to cause lactic acidosis. Multiple cases of hypoglycemia due to isolated metformin overdose have been reported. Increased glucose consumption secondary to anaerobic metabolism has been reported as a possible explanation.

Case presentation: A 23-year-old Arabic woman took $30 \mathrm{~g}$ of metformin. In the emergency department, 4 hours after of the event, she was fatigued but vitally stable. During her hospitalization, she had severe lactic acidosis, hypotension corrected with fluid boluses and vasopressors, and multiple episodes of hypoglycemia $(6.3 \mathrm{mg} / \mathrm{dL}, 38 \mathrm{mg} / \mathrm{dL}$, and $42 \mathrm{mg} / \mathrm{dL}$ ), requiring multiple 50\% dextrose-water boluses. The three hypoglycemic episodes occurred coincident with severe lactic acidosis. She improved after 24 hours of continuous renal replacement therapy.

Conclusions: Hypoglycemia can be induced by metformin toxicity in the absence of co-ingestants. A possible explanation of metformin-induced hypoglycemia is increased glucose consumption due to anaerobic metabolism, decreased oral intake, decreased liver glucose production, and decreased glucose absorption.
\end{abstract}

Keywords: Metformin, Hypoglycemia, Lactic acidosis

\section{Background}

Metformin is a biguanide derivative that controls glucose levels through gluconeogenesis reduction and glycogen breakdown inhibition [1]. It also prevents hyperglycemia by reducing gastrointestinal tract absorption of glucose as well as increasing insulin signaling and utilization of glucose [2]. In addition, metformin inhibits the activity of mitochondrial glycerol 3-phosphate dehydrogenase enzyme, which decreases the production of glucose from lactate and glycerol [3]. Accidental and intentional metformin overdoses are commonly reported. In metformin toxicity, lactic acidosis is the most common serious adverse event [4-8].

However, in diabetic patients on metformin monotherapy, cases of hypoglycemia have been reported [9]. It has also been noticed in animal studies with therapeutic doses of metformin [10]. In a 5-year chart review of metformin exposure cases that were reported to the American

\footnotetext{
* Correspondence: alshehriab7@gmail.com

${ }^{2}$ King Fahad Medical City, Riyadh, Saudi Arabia

Full list of author information is available at the end of the article
}

Association of Poison Control Center (AAPCC), hypoglycemia was reported in $112(2.8 \%)$ of 4072 cases and it was referred to decreased caloric intake, heavy exercise, or sulfonylurea co-ingestion [11]. There are multiple reports of metformin overdose-induced hypoglycemia. However, definitive exclusion of sulfonylurea co-ingestion or insulin use were lacking $[12,13]$. One case report of metformin toxicity reported recurrent hypoglycemia where co-ingestion of sulfonylurea or insulin use has been ruled out by extensive laboratory tests [14]. We report a case of metformin toxicity in a young girl who had recurrent hypoglycemic episodes despite the absence of any co-ingestion.

\section{Case presentation}

A 23-year-old Arabic single woman was brought to our emergency department (ED) by her family around 4 hours after intentional metformin ingestion. She was on metformin for weight reduction (her body mass index was 28), as she was found to have polycystic ovarian syndrome (PCOS). She ingested around 60 tablets of $500 \mathrm{mg}$ metformin as a suicide attempt after she

(c) The Author(s). 2018 Open Access This article is distributed under the terms of the Creative Commons Attribution 4.0 International License (http://creativecommons.org/licenses/by/4.0/), which permits unrestricted use, distribution, and reproduction in any medium, provided you give appropriate credit to the original author(s) and the source, provide a link to the Creative Commons license, and indicate if changes were made. The Creative Commons Public Domain Dedication waiver (http://creativecommons.org/publicdomain/zero/1.0/) applies to the data made available in this article, unless otherwise stated. 
Table 1 Blood investigation results upon emergency department arrival

\begin{tabular}{|c|c|c|}
\hline Test & Value & Normal range \\
\hline Sodium (mmol/L) & 139 & $136-145$ \\
\hline Potassium (mmol/L) & 4.5 & $3.5-5.1$ \\
\hline Chloride (mmol/L) & 107 & $95-110$ \\
\hline Urea (mmol/L) & 3.2 & $2.5-6.7$ \\
\hline Creatinine (umol/L) & 124.2 & $53.0-97.0$ \\
\hline Glucose (mg/dL) & 6.3 & $74-106$ \\
\hline Albumin (g/L) & 40 & $15-60$ \\
\hline Alkaline phosphatase (U/L) & 99 & $40-150$ \\
\hline Aspartate transaminase $(U / L)$ & 25 & $5-34$ \\
\hline Alanine transaminase $(\mathrm{U} / \mathrm{L})$ & 16 & $5-55$ \\
\hline Lipase (U/L) & 29 & $8-78$ \\
\hline Calcium (mmol/L) & 1.28 & $2.20-2.50$ \\
\hline Magnesium (mmol/L) & 0.82 & $0.66-1.07$ \\
\hline Phosphate (mmol/L) & 2.3 & $0.74-1.52$ \\
\hline Prothrombin time (sec) & 16.8 & $11.5-16.5$ \\
\hline Partial thromboplastin time (sec) & 32.4 & $26.0-39.0$ \\
\hline International normalized ratio & 1.3 & $0.9-1.2$ \\
\hline White blood cell (*10^9/L) & 14.8 & $4.0-11.0$ \\
\hline Red blood cell (*10^12/L) & 4.52 & $4.32-5.72$ \\
\hline Hemoglobin (g/L) & 143.0 & $135-175$ \\
\hline Hematocrit (\%) & 43 & $38-46$ \\
\hline Mean corpuscular volume (fL) & 96.3 & $80.0-94.0$ \\
\hline Mean cell hemoglobin (pg) & 31.8 & $27.0-32.0$ \\
\hline Mean cell hemoglobin concentration ( $g / L)$ & 330.0 & $320.0-360.0$ \\
\hline Platelet $\left({ }^{*} 10 \wedge 9 / L\right)$ & 361 & $150-450$ \\
\hline
\end{tabular}

experienced a stressful social event. Four years prior, she had undergone a kidney donation to her brother, who had renal failure due to an unknown cause, and otherwise she was healthy. She was not known to have any psychiatric illness or previous suicidal ideation or attempt. There was no history of smoking or alcohol intake. She does not have any family history of diabetes mellitus or mental illnesses. On examination, she was alert and well-nourished but generally fatigued, with no pallor, jaundice, or cyanosis. Her vital signs were as follows: blood pressure 119/65 $\mathrm{mmHg}$, heart rate 122 beat/min, respiratory rate 20 breaths/min, pulse oximetry oxygen saturation $100 \%$ on room air, and oral temperature $36.9{ }^{\circ} \mathrm{C}$. She had dry and cool skin, and bilaterally mid-sized pupils, equal and reactive. The rest of her physical examination was unremarkable.

Her bedside point-of-care capillary blood glucose level was checked, and it was low. A peripheral intravenous cannula was inserted, and blood extracted followed by administration of $50 \mathrm{ml}(25 \mathrm{~g})$ of $50 \%$ dextrose (D50) solution. Her blood glucose level was $6.3 \mathrm{mg} / \mathrm{dL}$ in serum chemistry; however, it increased to $106 \mathrm{mg} / \mathrm{dL}$ after the D50. After that, 5\% dextrose-water solution was initiated as a maintenance infusion. Her blood investigation results are summarized in Table 1. They were unremarkable except for a very low blood glucose level, leukocytosis, hypocalcemia, hyperphosphatemia, and mild creatinine elevation. An initial venous blood gases reading revealed $\mathrm{pH}$ : 7.18; $\mathrm{PO} 2$ : $76.9 \mathrm{mmHg}$; PCO2: $40.3 \mathrm{mmHg}$; and bicarbonate of $14.3 \mathrm{mmol} / \mathrm{L}$. Her first lactate level was elevated $(8.4 \mathrm{mmol} / \mathrm{L})$, and so a $1 \mathrm{~L}$ bolus of Ringer lactate solution was given. Her serial venous blood gases and lactate measurements are shown in Table 2. Results of analyses of her acetaminophen and aspirin levels were negative. In addition, urine analysis as well as urine pregnancy test results were negative.

Two hours later, her capillary blood glucose dropped to $38 \mathrm{mg} / \mathrm{dL}$, and another $50 \mathrm{~mL}$ ampule of D50 was infused, which increased her glucose level to $319 \mathrm{mg} / \mathrm{dL}$. During the hospital stay, her blood sugar was monitored frequently (Table 3). As our patient had worsening lactic acidosis, a nephrologist was urgently consulted, and she was admitted to the intensive care unit (ICU). She had a drop in her blood pressure, and so norepinephrine infusion was initiated. After that, continuous renal replacement therapy (CRRT) was started. At around 3 hours later, her blood sugar dropped to $42 \mathrm{mg} / \mathrm{dL}$, and another dextrose bolus was given. After 13 hours of CRRT initiation, the norepinephrine infusion was discontinued, and our patient was hemodynamically stable. The CRRT was continued for 24 hours. Our patient's renal and liver function tests did not worsen and remained within normal limits till hospital discharge.

On day 3 , she was transferred to the ward with normal mental status and vital signs. She was tolerating oral

Table 2 Venous blood gases and lactate levels

\begin{tabular}{|c|c|c|c|c|c|c|c|}
\hline & 25/4@ 2058 & 25/4@ 2323 & 26/4@04:05 & 26/4@10:19 & 26/4@ 1347 & 27/4@0531 & 27/4@1733 \\
\hline $\mathrm{pH}$ & 7.18 & 7.09 & 7.09 & 7.33 & 7.43 & 7.40 & 7.38 \\
\hline PCO2 (mmHg) & 40.3 & 28.9 & 37 & 33.0 & 33.6 & 45.3 & 36.0 \\
\hline $\mathrm{PO} 2(\mathrm{mmHg})$ & 76.9 & 89.0 & 35 & 41 & 93.2 & 45.9 & 30.0 \\
\hline HCO3 (mmol/L) & 14.3 & 10.0 & 11.2 & 13.3 & 23.5 & 26.7 & 21.3 \\
\hline Lactate (mmol/L) & 8.4 & 12.1 & $>13.3$ & 7.7 & 2.2 & 0.9 & 1.0 \\
\hline
\end{tabular}


Table 3 Blood glucose levels (mmol/L)

\begin{tabular}{|c|c|c|c|c|c|c|c|c|c|c|}
\hline $\begin{array}{l}25 / 4 \\
@ 2100\end{array}$ & $\begin{array}{l}25 / 4 \\
@ 2105\end{array}$ & $\begin{array}{l}25 / 4 \\
@ 2230\end{array}$ & $\begin{array}{l}25 / 4 \\
@ 23: 00\end{array}$ & $\begin{array}{l}25 / 4 \\
@ 2305\end{array}$ & $\begin{array}{l}25 / 4 \\
@ 2345\end{array}$ & $\begin{array}{l}26 / 4 \\
@ 0600\end{array}$ & $\begin{array}{l}26 / 4 \\
@ 0700\end{array}$ & $\begin{array}{l}26 / 4 \\
@ 0800\end{array}$ & $\begin{array}{l}26 / 4 \\
@ 0900\end{array}$ & $\begin{array}{l}29 / 4 \\
@ 1300\end{array}$ \\
\hline 6.3 & 106 & 65 & 38 & 319 & 95 & 127 & 88 & 42 & 145 & 119 \\
\hline
\end{tabular}

intake and did not develop any more hypoglycemic attacks. The psychiatrist was consulted for further assessment and treatment. On the fifth day of hospitalization, our patient was discharged home with a good health status. This patient was provided, as a part of our multidisciplinary discharge planning, with follow-up appointments within 1 month for internal medicine, nephrology, and psychiatry. As per our medical records, this patient did not show up for any of these outpatient follow-up appointments.

\section{Discussion}

In this case report, we describe the case of a young woman who developed significant hypoglycemia and a severe lactic acidosis after metformin ingestion. The patient required ICU admission and CRRT. There are numerous publications of metformin-induced hypoglycemia in the medical literature. In most cases the patients had in common that they were suffering malnutrition, performing strenuous exercise, or the patients had comorbidities or other toxic co-ingestions. The patient in our case report was a young woman without previous medical history other than PCOS. Our case is rare in comparison to the other publications about hypoglycemia because our patient was not malnourished and did not have a toxic co-ingestion.

The 2014 annual report of the American Association of Poison Control Centers (AAPCC) reported 8412 cases of biguanide ingestion with 35 major adverse events and 7 deaths [15]. In metformin toxicity, nausea, vomiting, and hyperglycemia were the most commonly reported adverse events, whereas hypoglycemia was reported in only $2 \%$ of the cases [16]. Zitzmann et al. reported a case of hypoglycemia in an elderly diabetic woman using therapeutic doses of metformin and ACE inhibitors, although her poor nutritional status was a concern [17]. In addition, hypoglycemia following metformin overdose was reported in a 43-year-old woman, and the authors considered that the hypoglycemia was secondary to a net result of metformin toxicity and decreased oral intake with renal impairment, however, co-ingestions were not excluded [12].

A case of hypoglycemia secondary to metformin overdose and kerosene co-ingestion was reported by Rathnapala et al. hypothesizing synergism, however, insulin use, or sulfonylurea co-ingestion could not be ruled out [13]. Other reported cases of metformin-related hypoglycemia were associated with heavy exercise, poor oral intake, sulfonylurea co-ingestion, or other comorbidities [18-20].

However, one case report of two episodes of hypoglycemia secondary to metformin toxicity was a previously healthy patient, who had normal nutritional status, and co-ingestion of sulfonylurea and insulin use was excluded by extensive laboratory tests [14]. Although, one explanation of the hypoglycemia was the

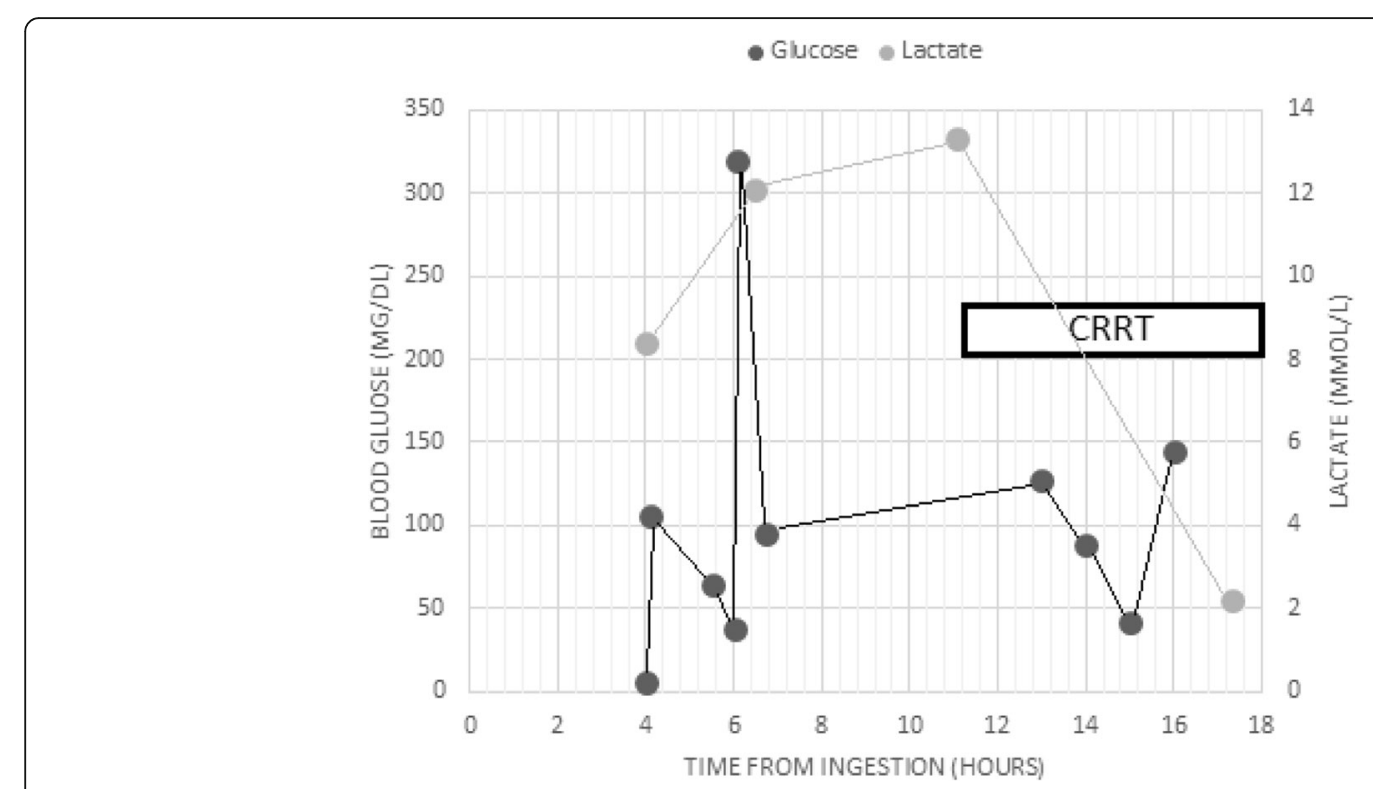

Fig. 1 Measurements of blood glucose and lactate levels. CRRT continuous renal replacement therapy 
increased consumption of glucose due to anaerobic metabolism that happened when lactic acidosis was at its peak [21]. Our patient developed three episodes of hypoglycemia that were corrected with dextrose boluses; however, these episodes were coincidental with severe lactic acidosis. (Fig. 1).

The peak level of lactate occurred before the CRRT was initiated. Our patient was responding very well to the CRRT, her lactic acidosis was resolving with time and her renal function remained intact during her hospital stay. In addition, the norepinephrine infusion was discontinued during CRRT with normal hemodynamic status.

Metformin absorption, liver uptake, and kidney elimination are affected by organic cation transporters (OCTs), with variation in liver uptake and clinical effects due to the differences in their expression level in the liver [2224]. Some drugs such as rifampin, may increase the metformin effects in decreasing glucose by affecting the OCTs action [25]. OCTs genetic polymorphism or existence of drugs which can affect them might explain the metformin-induced hypoglycemic cases [26]. Our patient strongly denied co-ingestion, however, it was not ruled out completely by advanced laboratory tests.

\section{Conclusions}

Hypoglycemia can be induced by metformin toxicity in the absence of other co-ingestions, and close monitoring of blood glucose is crucial. One possible explanation of metformin-induced hypoglycemia is increased glucose consumption secondary to anaerobic metabolism, however, other mechanisms like decreased oral intake, decreased liver glucose production, and decreased glucose absorption are of consideration.

\section{Abbreviations}

AAPCC: American Association of Poison Control Centers; CRRT: Continuous renal replacement therapy; D50: 50\% dextrose; ED: Emergency department; ICU: Intensive care unit; OCTs: Organic cation transporters

Availability of data and materials

All presented or analyzed data are included in this article.

\begin{abstract}
Authors' contributions
SA reviewed the literature and wrote the draft manuscript. AA reviewed the contents and was involved in writing and proofreading the body text of the manuscript. BM revised the scientific content and gave final approval for the version to be submitted. All the authors participated in writing and editing the manuscript, and approved the final manuscript.
\end{abstract}

\section{Ethics approval and consent to participate}

Not applicable.

\section{Consent for publication}

Written informed consent was obtained from the patient for publication of this case report. A copy of the written consent is available for review by the Editor-in-Chief of this journal.

\section{Competing interests}

The authors declare that they have no competing interests.

\section{Publisher's Note}

Springer Nature remains neutral with regard to jurisdictional claims in published maps and institutional affiliations.

\section{Author details}

${ }^{1}$ Princess Nourah bint Abdulrahman University, Riyadh, Saudi Arabia. ${ }^{2}$ King Fahad Medical City, Riyadh, Saudi Arabia.

Received: 30 December 2017 Accepted: 28 June 2018

Published online: 18 August 2018

\section{References}

1. Viollet B, Guigas B, Sanz Garcia N, Leclerc J, Foretz M, Andreelli F. Cellular and molecular mechanisms of metformin: an overview. Clin Sci (Lond). 2012;122:253-70.

2. Bell PM, Hadden DR. Metformin. Endocrinol Metab Clin N Am. 1997;26:523-37.

3. Madiraju AK, Erion DM, Rahimi Y, et al. Metformin suppresses gluconeogenesis by inhibiting mitochondrial glycerophosphate dehydrogenase. Nature. 2014;510:542-6.

4. Perrone J, Phillips C, Gaieski D. Occult metformin toxicity in three patients with profound lactic acidosis. J Emerg Med. 2011;40:271-5.

5. Salpeter SR, Greyber E, Pasternak GA, Salpeter EE. Risk of fatal and nonfatal lactic acidosis with metformin use in type 2 diabetes mellitus. Cochrane Database Syst Rev. 2010;(4):CD002967.

6. Von Mach MA, Sauer O, Sacha Weilemann L. Experiences of a poison center with metformin - associated lactic acidosis. Exp Clin Endocrinol Diabetes. 2004;112:187-90.

7. Galea M, Jelacin N, Bramham K, White I. Severe lactic acidosis and rhabdomyolysis following metfromin and ramipril overdose. $\mathrm{Br} J$ Anaesth. 2007:98:213-5.

8. Lacher M, Hermanns-Clausen M, Haeffiner K, Bradis M, Pohl M. Severe metformin intoxication with lactic acidosis in an adolescent. Eur J Pediatr. 2005;164:362-5.

9. Bodmer M, Meier C, Krähenbühl JSS, Meier CR. Metformin, sulfonylureas, or other antidiabetes drugs and the risk of lactic acidosis or hypoglycemia: a nested case-control analysis. Diabetes Care. 2008;31:2086-91.

10. Ashwell CM, McMurtry JP. Hypoglycemia and reduced feed intake in broiler chickens treated with metformin. Poult Sci. 2003:82:106-10.

11. Spiller HA, Quadrani DA. Toxic effects from metformin exposure. Ann Pharmacother. 2004;38:776-80.

12. Yang PW, Lin KH, Lo SH, Wang LM, Lin HD. Successful treatment of severe lactic acidosis caused by a suicide attempt with a metformin overdose. Kaohsiung J Med Sci. 2009;25:93-7.

13. Rathnapala A, Matthias T, Jayasinghe S. Severe lactic acidosis and acute renal failure following ingestion of metformin and kerosene oil: a case report. J Med Case Rep. 2012;6:18.

14. Al-Abri SA, Hayashi S, Thoren KL, Olson KR. Metformin overdose induced hypoglycemia in the absence of other antidiabetic drugs. Clin Toxicol (Phila). 2013:51(5):444-7.

15. Mowry JB, Spyker DA, Brooks DE, McMillan N, Schauben JL. 2014 Annua Report of the American Association of Poison Control Centers' National Poison Data System (NPDS): $32^{\text {nd }}$ Annual Report. Clinical Toxicol (Phila). 2015:53(10):962-1147.

16. Forrester MB. Adult metformin ingestions reported to Texas poison control centers, 2000 - 2006. Hum Exp Toxicol. 2008;27:575-83.

17. Zitzmann S, Reimannl R, Schmechel H. Severe hypoglycemia in an elderly patient treated with metformin. Int J Clin Pharmacol Ther. 2002;40:108-10.

18. Omari A, Yue DK, Twigg SM. Exercise, metformin and hypoglycemia, a neglected entity. Br J Diabetes Vasc Dis. 2005;5:106.

19. Mallick S. Metformin induced acute pancreatitis precipitated by renal failure. Postgrad Med J. 2004;80:239-40.

20. Gjedde S, Christiansen A, Pedersen SB, Rungby J. Survival following a metformin overdose of $63 \mathrm{~g}$ : a case report. Pharmacol Toxicol. 2003;93:98-9.

21. Protti A. One other explanation for hypoglycemia during metformin overdose. Clin Toxicol (Phila). 2013;51(6):515

22. Graham GG, Punt J, Arora M, Day RO, Doogue MP, Duong JK, et al. Clinical pharmacokinetics of metformin. Clin Pharmacokinet. 2011;50:81-98.

23. Ciarimboli G. Role of organic cation transporters in drug-induced toxicity. Expert Opin Drug Metab Toxicol. 2011;7:159-74

24. Shikata E, Yamamoto R, Takanr H, Shigemasa C, Ikeda T, Otsubo K, leiri I. Human OrGANIC cation transporter (OCT1 and OCT2) gene polymorphisms and therapeutic effects of metformin. J Hum Genet. 2007;52:117-22. 
25. Cho SK, Yoon JS, Lee MG, Lee DH, Lim LA, Park K, et al. Rifampin enhances the glucose-lowering effect of metformin and increases OCT1 mRNA levels in healthy participants. Clin Pharmacol Ther. 2011;89:416-21.

26. Tzvetkov MV, Vormfelde SV, Balen D, Meinekei I, Schmidt T, Sehrt D. The effects of genetic polymorphisms in the organic cation transporters OCT1, $\mathrm{OCT} 2$, and OCT3 on the renal clearance of metformin. Clin Pharmacol Ther 2009;86:299-306.

Ready to submit your research? Choose BMC and benefit from:

- fast, convenient online submission

- thorough peer review by experienced researchers in your field

- rapid publication on acceptance

- support for research data, including large and complex data types

- gold Open Access which fosters wider collaboration and increased citations

- maximum visibility for your research: over $100 \mathrm{M}$ website views per year 